\title{
A JUSTIÇA ELEITORAL E OS CONFLITOS NA FIXAÇÃO DE COMPETÊNCIA NAS HIPÓTESES DE CONEXÃO E CONTINGÊNCIA COM OS CRIMES ELEITORAIS
}

\author{
FRANCISCO IGOR CAVALCANTE FREITAS \\ Graduando em Direito pela Universidade Federal do Ceará \\ e estagiário do Tribunal Regional Eleitoral do Ceará.
}

Resumo: As hipóteses de fixação de competência da Justiça Eleitoral na seara penal, nos casos de conexão e continência com crimes eleitorais, não são tratadas de forma unânime pela doutrina, isso diante da ocorrência de conflito de competência criminal com a Justiça Federal ou com o Tribunal do Júri, existindo diversas soluções para cada um desses casos. Essas divergências não decorrem apenas de simples desencontros interpretativos acerca da aplicação de uma norma, envolvem também um conflito entre normas constitucionais e infraconstitucionais. Este trabalho parte de um estudo doutrinário sobre as soluções apresentadas pelos autores, visando mostrar cada uma dessas abordagens e discutir, sobre um viés que preze pela constitucionalização do Direito, quais seriam as melhores soluções para cada hipótese. Palavras-chave: processo; penal; eleitoral; competência; constituição.

\section{INTRODUÇÃO}

A Jurisdição é um poder-dever do Estado, o qual este deve aplicar o direito a fim de que sejam resolvidos conflitos substituindo as partes. No entanto, nenhum órgão jurisdicional pode exercer tal função de forma indiscriminada e ilimitada, existindo, dessa forma, regras para a distribuição de seu exercício, tendo cada órgão sua própria medida ou quantidade de jurisdição, ou seja, sua própria competência, na qual somente dentro dela é que se torna possível o exercício da função jurisdicional.

A função jurisdicional é, assim, uma só e, concomitantemente a isso, é atribuída abstratamente a todos os órgãos integrantes do Poder 
Judiciário, passando, porém, por um processo gradativo de concretização, até que se chegue à determinação do juiz concretamente competente para determinado processo (CINTRA; GRINOVER; DINAMARCO, 2014, p. 250). São estabelecidas, com isso, diversas regras que delimitam qual o juízo deve julgar determinada causa, surgindo, muitas vezes, confusões diante da extensão e complexidade da matéria, que acabam por gerar dúvidas acerca de qual órgão jurisdicional deve exercer a jurisdição em concreto.

Esse trabalho trata, portanto, desses conflitos na fixação de competência, especificamente acerca daqueles dentro da seara processual penal, e que envolvem a Justiça Eleitoral, baseando-se no fato de que, por ser especializada, possui competência para julgar os crimes eleitorais e as infrações conexas de competência da jurisdição comum (art. 35, inciso II, do Código Eleitoral - Lei n. ${ }^{\circ} 4.737 / 65$, c/c o art. 78, inciso IV, do Código de Processo Penal - Decreto-Lei n. ${ }^{\circ}$ 3.689), surgindo dúvidas na ocasião em que estas últimas são, em tese, quando individualmente consideradas, de competência do Tribunal do Júri e da Justiça Federal (art. 5, inciso XXXVIII, alínea “d”, e art. 109 da Constituição Federal, respectivamente), sendo estes os pontos a serem abordados neste artigo.

Esse tema se torna complexo pois envolve um desacordo interpretativo acerca das normas que regulam os presentes casos, com uma eventual incompatibilidade entre estas, inclusive com conflito hierárquico.

No decorrer deste trabalho, buscar-se-á mostrar todas as soluções possíveis, ao que tudo indica, trazidas pela doutrina para os presentes casos, mostrando sua viabilidade ou não, e sempre tentando, apesar da escassez, mostrar julgados dos Tribunais Superiores sobre os referidos problemas de fixação de competência.

\section{COMPETÊNCIA CRIMINAL DA JUSTIÇA ELEITORAL}

\subsection{ASPECTOS GERAIS}

Guilherme Nucci (2017, p. 213), acerca da competência, diz: “Tratase da delimitação da jurisdição, ou seja, o espaço dentro do qual pode determinada autoridade judiciária aplicar o direito aos litígios que lhe forem apresentados, compondo-os". Três principais aspectos são considerados 
pela doutrina na fixação da competência, quais sejam, a distribuição em razão da natureza da infração (ratione materiae), em razão da qualidade da pessoa processada (ratione personae) e em razão do local do crime ou do domicílio ou residência do réu (ratione loci).

Sobre o assunto, diz o art. 121 da Constituição Federal que Lei Complementar disporá sobre a competência dos tribunais, juízes e juntas eleitorais, porém, enquanto não editada, ficou recepcionado o Código Eleitoral como lei material complementar na parte que disciplina a organização e a competência da Justiça Eleitoral (MS 26.604, rel. min. Cármen Lúcia, j. 4-10-2007, P, DJE de 3-10-2008), dispondo, em seu art. 35, inciso II, que compete aos juízes eleitorais processar e julgar os crimes eleitorais e os comuns que lhe forem conexos, ressalvada a competência originária do Tribunal Superior e dos Tribunais Regionais. Tal regra repetiu aquela prevista na Constituição de 1969 (ou, se preferir, na de 1967, alterada pela EC n. ${ }^{\circ}$ 1) em seu art. 137, inciso VII.

Dessa forma, dispõe a Justiça Eleitoral de competência, prevista na Constituição Federal, em razão da matéria (ratione materiae) para julgar os crimes definidos como eleitorais, compreendendo também os comuns que lhes forem conexos, conforme o Código Eleitoral (Lei n. ${ }^{\circ}$ 4.737/65).

\subsection{CONEXÃO E CONTINÊNCIA}

Não obstante os critérios principais de fixação de competências já especificados, o Código de Processo Penal (Decreto-Lei n. ${ }^{0}$ 3.689), que possui aplicação subsidiária ao processo e julgamento dos crimes de competência da Justiça Eleitoral, em seu art. 69, inciso V, define que "Determinará a competência jurisdicional: [...] a conexão ou continência”. São eles dois institutos processuais penais que, latu sensu, fazem parte das regras de fixação de competência, embora, stricto sensu, modifiquem as convencionais regras de escolha do juiz natural, por atenderem a critérios de ordem puramente instrumental (NUCCI, 2017, p. 245), permitindo à lei modificar ou prorrogar a competência, a fim de se favorecer a celeridade processual, uma melhor visão do acervo probatório de dois ou mais crimes que guardam uma íntima relação entre si e também evitar decisões contraditórias.

Geram, portanto, a reunião de processos e a unidade de julgamento de causas interligadas em razão da força de atração exercida pelo juízo 
competente, causas estas que seriam, originalmente e em abstrato, julgadas por órgãos jurisdicionais diferentes, caso se levasse em consideração o lugar da infração, o domicílio do réu, a natureza da infração e a distribuição (LIMA, 2015, p. 554 e NUCCI, 2017, p. 256).

A fim de ilustração, seria o caso, por exemplo, o qual o prefeito de determinada municipalidade compra votos, em concurso com um de seus cabos eleitorais, de eleitores de uma determinada região, ambos praticando o crime previsto no art. 299 do Código Eleitoral (Lei n. ${ }^{\circ}$ 4.737/65): não faz sentido algum julgamento distinto, por mais que tenham se organizado para praticar ações diferentes.

\subsection{A ELEIÇÃO DO FORO DE ATRAÇÃO}

Como dito anteriormente, em razão da conexão e da continência, duas causas que poderiam ser apreciadas em processos diferentes em órgãos jurisdicionais distintos são, na verdade, reunidas em um desses órgãos, o juízo competente, que exerce a força atrativa.

Surge então a dúvida sobre qual seria o juízo de atração durante as hipóteses de conexão e continência que incluem os crimes eleitorais. Acerca do assunto, dispõe o art. 78, inciso IV, do Código de Processo Penal (Decreto-Lei n. ${ }^{\circ}$ 3.689), a prevalência da Justiça Eleitoral, por ser especial, sobre a jurisdição comum:

Art. 78. $\mathrm{Na}$ determinação da competência por conexão ou continência, serão observadas as seguintes regras:

I- no concurso entre a competência do júri e a de outro órgão da jurisdição comum, prevalecerá a competência do júri:

II- no concurso de jurisdições da mesma categoria:

a) preponderará a do lugar da infração, à qual for cominada a pena mais grave;

b) prevalecerá a do lugar em que houver ocorrido o maior número de infrações, se as respectivas penas forem de igual gravidade;

c) firmar-se-á a competência pela prevenção, nos outros casos;

III- no concurso de jurisdições de diversas categorias, predominará a de maior graduação;

$I V$ - no concurso entre a jurisdição comum e a especial, prevalecerá esta.

Sobre o mesmo problema, diz o art. 35, inciso II, do Código Eleitoral (Lei n. ${ }^{\circ}$ 4.737/65), que é de competência da Justiça Eleitoral processar e julgar tanto os crimes eleitorais quanto os comuns que lhe forem conexos. 
Com relação a isso, não surgem dúvidas quanto à hipótese de conexão e continência entre crimes eleitorais e os de competência da Justiça Comum Estadual, já que Justiça Eleitoral será competente para julgar ambos, por possuir a força atrativa. Seria o caso, conforme o exemplo de Edgard Magalhães Noronha (1998, p. 65), em que um indivíduo, violando o sigilo de voto, fere uma pessoa, praticando, respectivamente, os delitos do art. 213 do Código Eleitoral e art. 129 do Penal.

Os problemas, no entanto, surgem, de fato, no momento em que passa a haver conexão e continência com crimes em que seus julgamentos são atribuídos, abstratamente, ao Tribunal do Júri e a Justiça Federal, à medida que tais competências estão estabelecidas na Constituição Federal (art. 5, inciso XXXVIII, alínea “d”, e art. 109 da Constituição Federal, respectivamente) e a prevalência ou força atrativa da Justiça Eleitoral sobre a jurisdição comum em uma mera lei processual penal.

\section{CONEXÃO E CONTINÊNCIA DE CRIMES ELEITORAIS COM OS DE COMPETÊNCIA DA JUSTIÇA FEDERAL}

\subsection{SOLUÇÃO: SEPARAÇÃO DOS PROCESSOS}

A hipótese de separação dos processos parte do pressuposto de que, em decorrência das competências da Justiça Federal e da Justiça Eleitoral estarem previstas na própria Constituição (art. 109 e 121, respectivamente), a melhor solução seria aquela que preservasse os mandamentos constitucionais, não sendo possível às normas processuais penais alterar, mesmo em caso de conexão e continência, em decorrência da especialidade do crime eleitoral, competências expressamente estabelecidas pela Lei Maior, mesmo a Justiça Federal sendo considerada como comum, e o art. 78, VI, do Código de Processo Penal estabelecer a predominância da jurisdição especial.

Destarte, como grande ponto positivo, essa solução acarreta, diante desse indubitável conflito hierárquico, a prevalência da Constituição Federal em relação à legislação infraconstitucional, gerando, em consequência, a separação dos processos e a preservação da Lei Maior.

Essa opção é defendida por Renato Brasileiro de Lima (2015, pp. 397 e 398), que preleciona: 
[...] na medida em que a competência da Justiça Federal vem preestabelecida na própria Constituição Federal, não pode ser colocada em segundo plano por força da conexão e da continência, normas de alteração da competência previstas na lei processual penal. Afinal, é a lei processual que deve ser interpretada por meio da constituição, e não o contrário.

Já se pronunciou nesse sentido o Superior Tribunal de Justiça (STJ CC: 126729 RS 2013/0036278-6, Relator: Ministro MARCO AURÉLIO BELLIZZE, Data de Julgamento: 24/04/2013, S3 - TERCEIRA SEÇÃO, Data de Publicação: DJe 30/04/2013), afirmando que:

$\mathrm{Na}$ eventualidade de ficar caracterizado o crime do art. 299 do Código Eleitoral, este deverá ser processado e julgado na Justiça Eleitoral, sem interferir no andamento do processo relacionado ao crime de falso testemunho, porquanto a competência da Justiça Federal está expressamente fixada na Constituição Federal, não se aplicando, dessa forma, o critério da especialidade, previsto nos arts. 78, IV, do CPP e 35, II, do Código Eleitoral, circunstância que impede a reunião dos processos na Justiça especializada.

Esse entendimento também já foi utilizado pelo STJ em outros momentos, quando, por exemplo, se afirmou categoricamente que: "A conexão e a continência entre crime eleitoral e crime da competência da Justiça Federal não importa unidade de processo e julgamento" (CC n. ${ }^{\circ}$ 19.478/PR, relator o Ministro Fontes de Alencar, DJU 4/2/2002) ou que "não pode permanecer a força atrativa da jurisdição especial, pois ocorreria conflito entre normas constitucionais, o que não é possível em nosso ordenamento jurídico" (CC n. ${ }^{\circ} 39.357 / \mathrm{MG}$, relatora a Ministra Laurita Vaz, DJU 2/8/2004).

Esse é o argumento que deve prosperar a fim de se entender pela separação dos processos e não outro, pois em uma primeira e falha análise, teria como se pensar na separação dos processos ou na unidade de julgamento na Justiça Federal, pois esta seria também jurisdição especial, e não comum, em razão de ter sua competência sido fixada pela Constituição, não sendo possível ser sobreposta pela Eleitoral. Tal raciocínio, porém, não merece prosperar, pois a Justiça Federal é sim comum, e mesmo que seja considerada como especial, não é ela especializada em matéria eleitoral, o que inviabiliza a afirmação de sua competência nessa seara (GOMES, 2015, p. 300). 


\subsection{SOLUÇÃO: UNIDADE DE JULGAMENTO PELA JUSTIÇA ELEITORAL}

Essa solução parte do pressuposto de que o art. 78, inciso IV, do Código de Processo Penal, e o art. 35, inciso II, do Código Eleitoral, não fizeram nenhuma distinção ao se referir, respectivamente, à jurisdição e ao crime comum, devendo a Justiça Eleitoral se sobrepor tanto a Justiça Comum Estadual quanto a Federal.

Tal hipótese já fora acolhida pelo Supremo Tribunal Federal em um antigo julgado (STF - CC: 7033 SP, Relator: SYDNEY SANCHES, Data de Julgamento: 02/10/1996, Tribunal Pleno, Data de Publicação: DJ 29-11-1996 PP-47156 EMENT VOL-01852-01 PP-00116), em qual foi estabelecido que:

Em se verificando, porém, que há processo penal, em andamento na Justiça Federal, por crimes eleitorais e crimes comuns conexos, é de se conceder "Habeas Corpus", de ofício, para sua anulação, a partir da denúncia oferecida pelo Ministério Público Federal, e encaminhamento dos autos respectivos à Justiça Eleitoral de $1^{a}$ instância, a fim de que o Ministério Público, oficiando perante esta, requeira o que lhe parecer de direito.

Indubitavelmente fora prevista nenhuma distinção quando se determinou a prevalência da jurisdição especial (eleitoral) sobre a comum, mas esta solução não parece adequada, visto que ignora o mandamento constitucional que determina a competência da Justiça Federal. É, porém, a tese defendida por Júlio Fabbrini Mirabete (2005, p. 195) quando entende pela prevalência da Justiça Eleitoral sobre a comum, seja ela estadual ou federal.

\subsection{SOLUÇÃO: DIFERENCIAÇÃO ENTRE CONEXÃO E CONTINÊNCIA}

Apesar de muito semelhantes, os institutos da conexão e continência são distinguidos em nosso Código de Processo Penal e tratados em dois momentos diferentes: nos artigos 76 e 77 , respectivamente, cada um com suas hipóteses de incidência.

O presente meio resolutivo tem como base fundamental tal diferenciação, importando na utilização dos dois desfechos das soluções 
anteriores, quais sejam, a separação dos processos e a unidade de julgamento pela Justiça Eleitoral, um para a situação de conexão e o outro para o caso de continência.

Tal entendimento é adotado por Eugênio Pacelli (2012, p. 281), que diz:

Nesse sentido, como a competência da Justiça Eleitoral é também uma competência expressa na Constituição, parece-nos inteiramente aceitável o entendimento, tanto doutrinário quanto jurisprudencial, no sentido da aplicação do disposto no art. 78 , IV, a determinar o foro prevalente da Justiça Eleitoral quando em concurso ou concorrência com crimes da competência estadual ou federal. Isso, na hipótese de continência (art. 77, CPP), em que ocorre unidade de conduta, a reclamar unidade de resposta penal estatal.

Quando, porém, o concurso for decorrente de conexão, em que a reunião de processos presta-se mais a tutelar o proveito probatório do que a exigir de unidade da jurisdição, pensamos que a melhor solução será a separação dos processos, de modo a se preservar o juiz natural.

Para Tourinho Filho (2011, p. 359), a conexão ocorre quando houver um vínculo entre duas ou mais infrações que aconselha a junção dos processos, a fim de se propiciar ao julgador uma perfeita visão do quadro probatório e, assim, um melhor conhecimento dos fatos, permitindo uma melhor prestação jurisdicional. Já a continência, segundo o mesmo doutrinador (2011, p. 362), ocorreria quando o fato fosse o mesmo (coautoria e participação) ou ocorresse unidade da conduta (concurso formal).

Essa solução nos parece equivocada pois, apesar dessa distinção, ambos são muito semelhantes, tratados, na verdade, como uma unidade só: modificam a competência criminal, gerando os mesmos efeitos, quais sejam, a reunião de processos e a unidade de julgamento. Dessa forma, permitem, ambas, que o órgão jurisdicional tenha uma perfeita visão do quadro probatório, evitando-se, ademais, a existência de decisões contraditórias (LIMA, 2015, p. 550).

Entende-se, aqui, que o Código de Processo Penal distingue, sim, os dois institutos ao tratá-los em artigos diferentes, porém suas finalidades permanecem as mesmas, sendo tal diferenciação, a fim de se entender pela prevalência ou não da Justiça Eleitoral, demasiadamente rigorosa. 


\section{CONEXÃO E CONTINÊNCIA DE CRIMES ELEITORAIS COM OS DE COMPETÊNCIA DO TRIBUNAL DO JÚRI}

\subsection{SOLUÇÃO: SEPARAÇÃO DOS PROCESSOS}

A justificativa dessa hipótese é bastante semelhante àquela vista no item anterior, ou seja, de que tanto a competência da Justiça Eleitoral quanto a do Tribunal do Júri são definidas pela Constituição, e que somente a separação dos processos seria capaz de garantir o respeito à competência estabelecida pela mesma, para ambas as situações, mesmo o Código de Processo Penal prevendo a prevalência da jurisdição especial (no caso, a Justiça Eleitoral) sob a comum e o Código Eleitoral dispor que o julgamento dos crimes eleitorais e os comuns (o que inclui os dolosos contra a vida) que lhe forem conexos devam ser julgados, ambos, pela jurisdição especial eleitoral.

Haveria, assim, um conflito hierárquico entre a Constituição Federal e uma norma infraconstitucional, onde estaria afastada a incidência da segunda. Essa posição é defendida, a título de exemplo, por Guilherme Nucci (2017, p. 224), que expõe:

Não há que se argumentar com eventual conexão entre eles, deslocando o julgamento para a Justiça Eleitoral (matéria especial em relação à do júri), pela simples razão de que a conexão é prevista no Código de Processo Penal e não pode afastar a competência constitucional. Dessa forma, se houver uma fraude eleitoral e, em face disso, o membro da Junta Eleitoral for assassinado, deve haver separação dos julgamentos. O crime eleitoral seguirá para a Justiça Especial, enquanto o crime contra a vida - que eleitoral não é - dever ser julgado pelo Júri. Com isso, garante-se respeito à competência estabelecida pela Constituição Federal para ambas as situações. Não teria sentido invocar a conexão, prevista em lei ordinária, para subtrair do Júri um delito doloso contra a vida, tipicamente de sua competência. É a posição que atualmente defendemos.

Até mesmo Eugênio Pacelli (2012, p. 282 e 283), diferentemente de sua solução proposta para o concurso de competência com a Justiça Federal, entende pela separação dos processos, independentemente de o instituto processual penal em questão ser a conexão ou a continência.

Perfilham também do entendimento, por exemplo, Aury Lopes Jr (2011, p. 471), Nestor Távora (2016, p. 436) e Renato Brasileiro de Lima (2014, p. 369). 


\subsection{SOLUÇÃO: UNIDADE DE JULGAMENTO NA JUSTIÇA ELEITORAL}

É possível entender também que os crimes dolosos contra a vida, quando em conexão com crimes eleitorais, devem também ser julgados pela Justiça Eleitoral, apesar de a Constituição Federal consagrar a competência para julgamento de tais infrações pela instituição do júri, inclusive como direito fundamental (art. 50, inciso XXXVIII, alínea “d”).

Dessa forma, com base nesta hipótese, quando houver concorrência entre o Tribunal do Júri e a Justiça Eleitoral, deveria ser competente esta última, em decorrência do art. 78, IV do Código de Processo Penal e do art. 35, inciso II, do Código Eleitoral.

Ocorreria, assim, em tese, um conflito hierárquico entre uma lei processual penal e a Constituição Federal, porém esta solução não entende pela sua existência, já que o próprio preceito constitucional, ao reconhecer a instituição do júri, estabeleceu a organização que lhe der a lei que, por sua vez, o inseriu no âmbito da Justiça Comum (GOMES, 2000, p. 57), logo, sempre restaria prevalente a competência da Justiça Eleitoral.

Tourinho Filho (2011, p. 366) preleciona nesse sentido:

Assim, sendo o homicídio crime comum e a Justiça Eleitoral, especial, prevalece esta. [...] É verdade que a Constituição dispõe ser da alçada do Tribunal do Júri o julgamento dos crimes dolosos contra a vida, consumados ou tentados. Mas, no exemplo dado, perderá ele a sua competência para julgar o crime doloso contra a vida. É que a Constituição pode excepcionar a si própria.

Outro argumento é o de que deve prevalecer esta solução em decorrência de o Código Eleitoral estabelecer que a Justiça Eleitoral deve julgar os crimes eleitorais e os comuns que lhe forem conexos, sem fazer nenhuma distinção. Essa é a opinião de José Frederico Marques (1953, p. 294) quando, se referindo a Constituição Federal de 1946, que repete a regra do Código Eleitoral, diz: "Se, entretanto, houver concurso de jurisdição entre o júri e a justiça eleitoral, prevalecerá a competência desta, pois a Constituição, no artigo 119 , n. ${ }^{\circ}$ VII, fala em crimes comuns, sem estabelecer distinção de qualquer espécie." 
Os defensores desta posição, em síntese, entendem não haver infringência a Lei Maior, devendo prevalecer a competência da Justiça Eleitoral para julgar ambos os crimes, seja em caso de conexão ou de continência.

\subsection{SOLUÇÃO: UNIDADE DE JULGAMENTO POR TRIBUNAL DO JÚRI ORGANIZADO NA JUSTIÇA ELEITORAL}

Esta solução visa preservar tanto o mandamento constitucional que define a competência da Justiça Eleitoral, quanto aquele que determina a competência do Tribunal do Júri para julgamento dos crimes dolosos contra a vida.

Argumenta-se, aqui, que o júri constitui mero procedimento, e não órgão jurisdicional dotado de esfera de competência própria, sendo importante que tal procedimento seja observado, pois é apenas isso que impõe a Lei Maior (GOMES, 2015, p. 300).

Argumento em favor dessa hipótese é o de que a Justiça Eleitoral é uma "justiça emprestada", não possuindo seus próprios juízes, que, na verdade, são magistrados da Justiça Comum exercendo, ao mesmo tempo, as funções de juiz eleitoral. Não haveria assim, óbice para um eventual Tribunal do Júri organizado na Justiça Eleitoral e não na Comum, posto que o julgamento, para ambos, seria presidido por magistrado, em tese, da jurisdição não especial, que é justamente onde está inserida a instituição do júri. Parte, também, do pressuposto de que a Justiça Eleitoral integra o Poder Judiciário Federal, podendo-se aplicar, neste caso, a norma regulamentadora do júri na esfera federal.

Entendemos, na verdade, que essa hipótese desrespeita a Constituição Federal em seu art. 5, inciso XXXVIII, que define a competência do Tribunal do Júri, pois permite a lei a instituição do júri organizado no âmbito da Justiça Eleitoral. É assim o entendimento de Suzana de Camargo Gomes (2000, p. 58):

Nesses casos, não há que se cogitar nem mesmo a hipótese da criação de um Tribunal do Júri de natureza eleitoral, posto que não previsto na lei que define a organização dessa instituição, nem tampouco na legislação eleitoral. É que não autoriza a lei a constituição de Tribunal 
do Júri no âmbito da Justiça Eleitoral, não havendo, destarte, que se falar possa o Juiz Eleitoral realizar a condução e presidência do processo afeto ao tribunal popular, pois, se assim fosse, estaria sendo desrespeitado o art. $5^{\circ}$, XXXVIII, da CF, que determina tenha a instituição do júri a organização que a lei lhe conferir

\subsection{SOLUÇÃO: UNIDADE DE JULGAMENTO POR JÚRI FEDERAL}

É, sem dúvida, a hipótese de maior diferença em relação às outras, pois prevê o de julgamento, quando houver conexão e continência, do crime doloso contra a vida e do crime eleitoral por um Tribunal do Júri organizado na Justiça Federal, principalmente por não haver previsão legal para a organização de um júri na esfera eleitoral.

Esta hipótese praticamente não possui acolhimento na doutrina, sendo defendida por Luiz Carlos dos Santos Gonçalves (2012, p. 156), que explica:

Se a morte de alguém é intentada com finalidade eleitoral, em conexão com crime eleitoral próprio, o assassino há de ser levado a júri popular, mas não vemos razão para que seja um Tribunal do Júri da Justiça Comum Estadual. Deve ser um Tribunal do Júri Federal, posto que a Justiça Eleitoral tem caráter federal.

Nos parece impossível essa hipótese, tanto porque, conforme referido, a Justiça Federal não é especializada em matéria eleitoral, o que inviabiliza a afirmação de sua competência nessa seara (GOMES, 2015, p. 300), quanto em razão de não existir dispositivo normativo que determine, de algum modo, a prevalência da jurisdição comum sobre a especial: na verdade está previsto o contrário. Restaria prejudicada, além disso, a competência constitucional da Justiça Eleitoral.

\section{CONSIDERAÇÕES FINAIS}

Da análise dos conflitos aqui apresentados, algo sempre perpassa a todos: o desrespeito, ou não, da Constituição Federal. Acreditamos, aqui, em decorrência da pirâmide hierarquia normativa, que sempre a melhor hipótese é aquela que salvaguarda a Lei Maior, mesmo em conflito da legislação infraconstitucional, pois é ela que embasa todo o ordenamento jurídico, e não o contrário. 
Dessa forma, entende-se que, hoje, o Direito é constitucionalizado, e isso implica que a Constituição está presente em todas as searas jurídicas, gerando dois fenômenos distintos, quais sejam, a constitucionalizaçãoinclusão e a constitucionalização releitura, estando esta última ligada a impregnação de todo o ordenamento jurídico pelos valores constitucionais, passando a nortear a interpretação da totalidade da ordem jurídica, submetendo os preceitos legais, os conceitos e os institutos infraconstitucionais a uma filtragem constitucional, impondo significativas mudanças na sua compreensão e em suas aplicações concretas (NETO e SARMENTO, 2013, pp. 40 e 41).

Assim, seguindo esse viés, entendemos que a melhor solução é aquela que prevê a separação dos processos em caso de conexão e continência de crimes eleitorais com aqueles de competência da Justiça Federal e do Tribunal do Júri, pois são estas abordagens que estão de acordo com a Constituição Federal.

Não se quer aqui afastar, de forma absoluta, o Código de Processo Penal ou o Código Eleitoral, mas sim deixar de modificar a competência criminal nesses casos de conexão e continência, entendendo-os de forma diferente, não literal, mas, sim, aos moldes da Lei Maior, que serve, além de tudo, como norte para o intérprete na aplicação de determinada norma infraconstitucional.

\section{REFERÊNCIAS}

CINTRA, Antônio Carlos De Araújo; GRINOVER, Ada Pellegrini; DINAMARCO, Cândido Rangel. Teoria geral do processo. 30 ed. São Paulo: Malheiros, 2014. 448 p.

GOMES, José Jairo. Crimes e processo penal eleitorais. São Paulo: Atlas, 2015. 328 p.

GOMES, Suzana De Camargo. Crimes eleitorais. São Paulo: Revista dos Tribunais, 2000. 343 p.

GONÇALVES, Luiz Carlos Dos Santos. Crimes eleitorais e processo penal eleitoral. São Paulo: Atlas, 2012. 190 p. 
LIMA, Renato Brasileiro De. Manual de processo penal. 3 ed. Salvador: JusPodivm, 2015. 1826 p.

LOPES JR., Aury. Direito processual penal e sua conformidade constitucional: vol. 1. 7 ed. Rio de Janeiro: Lumen Juris, 2011.736 p.

MARQUES, José Frederico. Da competência em matéria penal. 1 ed. São Paulo: Saraiva, 1953. 335 p.

MIRABETE, Júlio Fabbrini. Processo penal. 17 ed. São Paulo: Atlas, 2005. 849 p.

NETO, Cláudio Pereira de Souza; SARMENTO, Daniel. Direito constitucional: Teoria, bistória e métodos de trabalho. 1. Belo Horizonte: Fórum, 2013. 631 p.

NORONHA, Edgard Magalhães. Curso de direito processual penal. 26 ed. São Paulo: Saraiva, 1998. 654 p.

NUCCI, Guilherme De Souza. Manual de processo penal e execução penal. 14 ed. Rio de Janeiro: Forense, 2017. 1052 p.

PACELLI, Eugênio. Curso de processo penal. 16 ed. São Paulo: Atlas, 2012. $979 \mathrm{p}$.

SILVA, Viviane Vieira Da. A justiça eleitoral e o tribunal do júri. Resenha Eleitoral, Santa Catarina, v. 6, n. 2, jul./dez. 1999. Disponível em: <https://www. tre-sc.jus.br/site/resenha-eleitoral/revista-tecnica/edicoes-impressas / integra/2012/06/a-justica-eleitoral-e-o-tribunal-do-juri/index207f. html?no_cache $=1 \& \mathrm{cHash}=$ fef326190597c20d97ec58834dabe8be $>$. Acesso em: 01 ago. 2017.

TOURINHO FILHO, Fernando Da Costa. Manual de processo penal. 14 ed. São Paulo: Saraiva, 2011. 1007 p. 